\title{
Study about Influence of Policy Deficiency on College Sci-tech Achievement Transformation Resistance
}

\author{
Qiaohui Xu \\ College of Management \\ Wuhan University of Science and Technology \\ Hubei, China \\ 1156412927@qq.com
}

\author{
Tao Chen \\ College of Management \\ Wuhan University of Science and Technology \\ Hubei, China \\ 2763065171@qq.com
}

\begin{abstract}
Stressing on the implementation of innovation driven development strategy, accelerating the transformation of economic development mode, adjusting and optimizing the industrial structure, it is the way to enhance the driving force of scientific and technological innovation. The government policy plays a significant role in college sci-tech achievement transformation, however, the implementation effect is not obvious, and does not convert the situation of low conversion rate of scientific and technological achievements. So the imperfect of policy implementation, to some extent, inhibit sci-tech achievement transformation. This paper uses the methods of literature analysis and practical investigation and combines with the perspective of innovation resistance, to analyze the influence of policy deficiency, non-implementation and conflicts between policies and regulations on transformation resistance of college scientific researchers. Based on this, the paper puts forward some suggestions for improvement; meanwhile it offers theoretical and practical guidance for improving the plight of college sci-tech achievement transformation, enhancing policy implementation effect and promoting effective sci-tech achievement transformation.
\end{abstract}

Keywords_-policy deficiency; innovation resistance; innovation diffusion; sci-tech achievement transformation.

\section{INTRODUCTION}

As everyone knows, in promoting the construction of collaborative innovation system and realizing the industrialization of scientific research, colleges shoulder the mission of creating knowledge and sci-tech achievements and also bear the heavy task of transforming sci-tech achievements. But some data show that there are over 30000 sci-tech achievement annually at provincial level or above in China, where only $10 \%-15 \%$ can generate scale merit. There are more than 70000 patented technologies annually, but the implementation rate is only $10 \%$. Thus, large quantities of scitech achievements are not transformed.

Based on such theory and practical background, this paper deeply studies the influence of policy deficiency on college scitech achievements, i.e. the influence of policy deficiency on sci-tech achievement creators. In addition, the effect of policy deficiency on transformation resistance of college scientific researchers is researched in combination of innovation resistance theory. Based on such analysis, sole the problems of scientific researchers in practical transformation and increase transformation possibility.

\section{SystematiC ANALYSiS OF SCI-TECH ACHIEVEMENT TRANSFORMATION RESISTANCE}

\section{A. Definition of sci-tech achievement transformation}

Sci-tech achievement transformation mainly refers to follow-up experiment, development, application and popularization of sci-tech achievements with practical value which come from research and technology development until new products, new technology, new materials form and new industry develops in order to improve productivity level. [1]

\section{B. Relevant researches on sci-tech achievement} transformation resistance

The concept of innovation resistance came from psychology field at first, and it was put forward by the psychologist Heider. During studying human perception of new things, he mentioned that innovation resistance refers to human habitual resistance of new things and that it is a natural phenomenon. Sheth and Ram analyzed the formation reasons for innovation resistance, mainly including consumers' behavioral habit and perceived risk from innovative product application. Besides, Ram also established consumer innovation resistance model which mainly includes three modes: refuse application, delay application and oppose application. Current researches on innovation resistance mainly focus on new product diffusion field. Nielsen data show for every 10 new products, only 1 can achieve success in the market. It thus can be seen that the risks of new product diffusion are very large. Moreover, the survey data of $\mathrm{Ge}$ Jianping show the number of college sci-tech achievements in China which pass the appraisal annually is about 10000 , while only $15 \%-20 \%$ of sci-tech achievements can be transformed into practical productivity. This proportion of western developed countries is as high as $60 \%-80 \%$. Thus, new product diffusion and sci-tech achievement transformation have the similarity in essence. Hence, the researches on innovation resistance in new product diffusion may be applied for reference in the study on sci-tech achievement transformation. 
Some scholars studied sci-tech achievement transformation resistance. Han Junde and Li Hui (2011) applied multiple statistical analysis techniques and drew such conclusion that insufficient personnel investment, insufficient motivation and insufficient fund investment are the key obstacles hindering sci-tech achievement transformation. Jung and Lee et al. (2015) adopted classification tree and frequency analysis to research the factors influencing the success and failure of 583 sci-tech achievement transformation cases of public research institutes and private enterprises in South Korea from 1999 to 2006 and gained such conclusion that "insufficient fund", "market condition deterioration" and "insufficient market capacity" are the major obstacles in the three stages respectively: technology acquisition, sample test and product manufacturing. [2]Due to high risks and multiple obstacles of sci-tech achievement transformation, many sci-tech achievement creators are unwilling or cannot transform their sci-tech achievements and thus generate innovation resistance, resulting in low sci-tech achievement transformation rate.

\section{Definition OF Policy Deficiency AND Dimensional ANALYSIS}

Deficiency refers to defect or incompleteness. Policy deficiency mainly refers to negative effects in the implementation of specific policies, such as nonimplementation of policies, imperfect policies and conflicts with other laws and regulations. As a result, the expected effect fails to be gained in the policy implementation process, or the opposite effect is obtained. Martin Kenney (2009) et al. studied the attribution of invention ownership and indicated that policy incompleteness hinders research enthusiasm of scientific researchers, leads to the conflict between colleges and patent investors and thus restricts sci-tech achievement transformation.[3]Anna (2015) stated that government measures could promote knowledge and technology to transfer to enterprises, but some existing system defects hinder effective transfer of knowledge and technology. [4]

Therefore, policy deficiency largely affects sci-tech achievements transformation. However, current statement about policy deficiency is relatively general, and there is no detailed dimension. This paper tries to divide its dimension to explore the deep policy causes for sci-tech achievements transformation resistance. Zhu Lin (2014) pointed out that the deficiency of current technology management policy mainly includes the problems in the implementation process, such as pertinence and foresight deficiency in the aspect of technology policy, non-strict evaluation policy and unsound review system and support policy. Li Lingjuan and Huo Guoqing (2014) systematically reviewed existing policies based on achievement transformation chain and found that policy and regulation conflict exists in sci-tech achievement property ownership and income distribution mechanism, and policy incompleteness and policy non-implementation problems exist in technology transfer, technology investment, sci-tech achievement financing and industrialization.[5] Jiang Xinghua, Xie Huiru and Ma Weihua (2016) indicated that institutional factors restricting sci-tech achievement transformation mainly include poor policy coordination and implementation effect, policy regulation against transformation, policy fuzziness and adverse policy environment etc.[6] Based on the above literature summary and field investigation, policy deficiency is divided into three aspects: policy incompleteness, policy non-implemen -tation and conflict between the policy and regulations.

\section{STUDY ABOUT INFLUENCE OF POLICY DEFICIENCY ON COLLEGE SCI-TECH ACHIEVEMENT TRANSFORMATION RESISTANCE}

\section{A. Influence of policy incompleteness on college sci-tech achievement transformation resistance}

In college sci-tech achievement transformation, transformation obstacles and risks are huge. For scientific researchers, if the risks surpass the range they can bear, they will not consider transformation. Thus, when the policy is not perfect enough to solve the risks, they will not consider transformation, which results in resistance.

Although the state has issued relevant policies to facilitate sci-tech achievement transformation, the process of sci-tech achievement transformation is complex and involves multiple subjects. The non-coordination of national, local and college policies also causes scientific researchers are at a loose end. This to a large extent affects enthusiasm of scientific researchers. During researching agricultural sci-tech achievement transformation, Liu Wenhua (2016) found that unclear governmental duty positioning and the lack of organizational cooperatively because that scientific researcher cannot go deep to the forefront of production and transform sci-tech achievements in time. In addition, some scholars indicated that poor policy coordination and restricted execution also dispel enthusiasm of scientific researchers, thus leading to their abandonment of sci-tech achievement transformation. When analyzing the attribution of invention ownership, Martin Kenney (2009) et al. indicated that the attribution of ownership to the university may hinder research enthusiasm of scientific researchers and even lead to the conflict between the university and the patent inventor, thus inhibiting sci-tech achievement transformation. Thus, policy incompleteness enhances personal perceived risk of scientific researchers so that they are unwilling to transform their products.

\section{B. Influence of policy non-implementation on college sci-tech achievement transformation resistance}

Colleges serve as the important source of sci-tech achievement output, and transformation issue has been valued by the state. The state also has formulated quite many policies for regulation and control. But in the practical implementation process, the efficacy of policies is not reflected. Nowadays, stock incentive system of state-owned sci-tech enterprises is an example. Due to the lack of upper limit for the award of scientific and technical personnel and the loss of state-owned assets, the stock right of state-owned sci-tech enterprises cannot be implemented effectively. Thus, working enthusiasm of scientific and technical personnel in state-owned enterprises decreases and gives up sci-tech achievement transformation. Lu Zhangping and Wang Xiaojin (2013) applied UCINET software to analyze the documents about sci-tech achievement transformation in 1980-2011 and used Net-Draw visual tool to evaluate the application situation of policy instrument. They 
found that poor policy binding force and operability enhance the transformation difficulties of scientific researchers so that they are unwilling to transform their achievements. [7] Policy non-implementation problem exists in technology transfer, technology investment, sci-tech achievement financing and industrialization so that various problems occur in sci-tech achievement transformation and hinder sci-tech achievement transformation.

\section{Influence of conflict between the policy and regulations on college sci-tech achievement transformation resistance}

Both policies and regulations are formulated by the government to safeguard sci-tech achievement transformation. Current sci-tech achievement transformation policy mainly promotes sci-tech achievement transformation, while regulations safeguard the benefits of each party in sci-tech achievement transformation. The two may conflict with each other. According to the field survey, a professor of Tsinghua University invented a patent during work and predicted it might achieve a great success. But since it is an on-duty invention, the law specifies that most income shall belong to the university. This conflicts with promotion of sci-tech achievement transformation and also kills transformation enthusiasm of scientific researchers. Finally, effective sci-tech achievement transformation is delayed. Moreover, state-owned property management method of public institutions and relevant tax policies conflict with the law of sci-tech achievement transformation, which hinders sci-tech achievement transformation of state-owned enterprises. Furthermore, inconformity between policies and regulations often make scientific researchers at a loose end and unwilling to transform their sci-tech achievements.

\section{Policy Suggestions on SCI-TeCH ACHIEVEMENT TRANSFORMATION}

\section{A. To improve relevant policies and promote management system reform}

Sci-tech achievement transformation is a complex activity which involves many subjects, so it is necessary to enhance coordination and connection of each government department, make the policy of sci-tech achievement transformation more complete and form the resultant force of policies to facilitate sci-tech achievement transformation. On the basis of implementing the work of respective department, the Ministry of Science and Technology and other management departments should further effectively integrate achievement transformation policies and regulations of each department, promote organic combination and unification of sci-tech achievement transformation policies and other policies, boost the support rate of sci-tech achievement transformation policies and reduce transformation difficulties of scientific researchers so as to better mobilize the transformation enthusiasm of scientific researchers.

\section{B. To pay attention to policy implementation and enhance supervision and management}

The government should issue the implementation rules of Law of the PRC on Promoting the Transformation of Scientific and Technological Achievements and promote cooperation among enterprises and the cooperation among enterprises, universities sand scientific research institution. In addition, the policies and mechanism orientation about industry-universityresearch cooperation should be issued as soon as possible, such as institution setting, personnel turnover, income distribution and intellectual property guarantee. Meanwhile, it is required to improve legal system of sci-tech achievement transformation, strengthen law enforcement force and judicial protection, facilitate improvement and implementation of legal system of sci-tech achievement transformation, dispel misgivings of scientific researchers and promote more effective sci-tech achievement transformation.

\section{To coordinate policies and regulations and keep consistent policies and laws}

Relevant laws and regulations should be modified as per the development conditions of economic society and intellectual property to simplify the procedures of application for intellectual property registration, make legal procedure of application for intellectual property registration strict, provide convenient and considerate services for intellectual property applicants, enhance intellectual property protection force and form independent intellectual property policy and regulation system. It is also required to make policies and regulations adapt to each other so as to motivate research enthusiasm of scientific researchers.

\section{CONCLUSIONS}

College sci-tech achievement transformation has been an important topic in the field of college development and technological innovation. This paper mainly combines innovation resistance theory to explore the policy factor of college sci-tech achievement transformation failure and contributes to studying sci-tech achievement transformation from a new perspective. In future, other factors influencing college sci-tech achievement transformation maybe further explored, and relevant empirical analysis may be carried out to provide theoretical support for promoting sci-tech achievement transformation in China.

\section{REFERENCES}

[1] Huang Chuanhui, Zheng Yanning, Wu Chunyu, Research on American Sci-tech Achievement Transformation Mechanism [J]. Hubei Social Sciences, 2011(10):81-83.(In Chinese)

[2] Jung M, Lee Y B, Lee H. Classifying and prioritizing the success and failure factors of technology commercialization of public R\&D in South Korea: using classification tree analysis[J]. The Journal of Technology Transfer, 2015, 40(5):877-898.

[3] Kenney M, Patton D. Reconsidering the Bayh-Dole Act and the Current University Invention Ownership Model[J]. Research Policy, 2009, 38(9):1407-1422.

[4] Kochenkova A, Grimaldi R, Munari F. Public policy measures in support of knowledge transfer activities: a review of academic literature[J]. Journal of Technology Transfer, 2015, 41(3):1-23.

[5] Li Lingjuan, Huo Guoqing, Zeng Mingbun et al., Policy Review Based on Value-chain of Technology Transfer [J]. Scientific Management Research, 2014(1):10-14. (In Chinese)

[6] Jiang Xinghua, Xie Huiru, Ma Weihua, Question and Countermeasure Research on the Transformation of Scientific and Technological 
Achievement Based on the Perspective of Policy Analysis [J]. Science and Technology Management Research, 2016, 36(2):54-59.
[7] Lu Zhangping, Wang Xiaojing, Study on Sci-tech Achievement Transformation Policy Based on Content Analysis Method [J]. Science \& Technology Progress and Policy, 2013, 30(11):98-103. 